\title{
PENGARUH PENDEKATAN INKUIRI TERBIMBING BERBANTUAN MODUL BELAJAR TERHADAP KETERAMPILAN PROSES SAINS, DAN HASIL BELAJAR PSIKOMOTORIK
}

\author{
Neneng Agustiningsih ${ }^{1}$, Moh. Amin ${ }^{2}$, dan Mimien ${ }^{3}$ \\ 1 Pascasarjana Pendidikan Biologi Universitas Negeri Malang \\ ${ }^{2 \& 3}$ Fakultas Pendidikan Biologi Universitas Negeri Malang \\ Email: Ne2ng08@gmail.com
}

\begin{abstract}
Abstrak
Penelitian ini bertujuan untuk menjelaskan pengaruh pendekatan inkuiri terbimbing berbantuan modul belajar terhadap keterampilan proses sains, dan hasil belajar psikomotor. Rancangan penelitian yang digunakan ialah kuasi eksperimen dengan Pretest-Postest Non equivalent Control Group Design. Penelitian dilaksanakan di SMP Laboratorium UM Malang tahun ajaran 2013/2014. Sampel penelitian adalah peserta didik kelas VIII C sebagai kelas perlakuan, dan VIII B sebagai kelas kontrol. Keterampilan proses sains di ukur menggunakan tes uraian, dan hasil belajar psikomotorik di ukur menggunakan lembar pengamatan, dan rubrik pengamatan psikomotorik. Instrumen tes terlebih dahulu diuji validitas dan reliabilitas. Data diambil pada saat pretes, postes. Uji hipotesis menggunakan anakova dengan taraf signifikansi 0,05 $(\mathrm{P}<0,05)$. Sebelum uji anakova, dilakukan uji normalitas data dengan uji kormogolov-smirnov dan uji homogenitas data dengan Levene tes. Hasil penelitian menunjukkan:1) pendekatan inkuiri terbimbing berbantuan modul belajar berpengaruh terhadap keterampilan proses sains, dan 2) pendekatan inkuiri terbimbing berpengaruh berbantuan modul belajar terhadap hasil belajar psikomotorik. Melihat potensi dari pendekatan inkuiri terbimbing berbantuan modul belajar dapat diaplikasikan dalam pembelajaran kurikulum 2013.
\end{abstract}

Kata kunci: Pendekatan Inkuiri Terbimbing, Keterampilan Proses Sains, Hasil Belajar Psikomotorik. 


\section{PENDAHULUAN}

Pembelajaran dalam konteks mempersiapkan sumber daya manusia abad 21 mengacu pada konsep belajar yang memberi pengalaman langsung kepada peserta didik. Proses pembelajaran yang tengah diterapkan merupakan pembelajaran berbasis kompetensi dan karakter yang berimplikasi pada perolehan belajar peserta didik, serta menguasai keterampilan hidup (life skills), salah satunya adalah keterampilan kerja ilmiah (Departemen Pendidikan Nasional, 2002).

Pendekatan inkuiri terbimbing merupakan pendekatan yang dapat memberdayakan, dan mengembangkan keterampilan proses sains dengan memberikan kesempatan berpikir dan pemahaman konsep kepada peserta didik melalui pengalaman belajar. Pembelajaran inkuiri terbimbing dalam pelaksanaanya menurut Lane (2007) memiliki kelebihan, meliputi: memungkinkan guru membantu peserta didik belajar tentang suatu materi atau konsep dengan mengekspor pertanyaan dan mengembangkan hipotesis, menjadikan peserta problem solver yang cukup baik, mengembangkan sikap percaya diri peserta didik tentang apa yang ditemukan dalam proses inkuiri, serta menjadikan peserta didik menjadi pemikir kritis yang baik. Hal ini diperkuat dengan penelitian Supatmo (2009) menghasilkan kesimpulan bahwa; (a) penerapan pembelajaran inkuiri dapat meningkatkan keterampilan proses sains, (b) meningkatkan hasil belajar fisika peserta didik, dan (c) dapat meningkatkan ketuntasan belajar peserta didik. Pendekatan inkuiri dengan prosesnya yang menuntut peserta didik untuk melakukan kegiatan sistematis dalam menemukan konsep, pengamatan, dan percobaan. Dari kelebihan pendekatan inkuiri terbimbing ini membantu peserta didik khususnya pada materi biologi dalam proses belajarnya, hal ini sesuai dengan pendapat Depdiknas (2001) menyatakan bahwa, pendidikan Biologi menekankan pada pemberian pengalaman secara langsung, oleh karena itu peserta didik perlu dibantu untuk mengembangkan sejumlah keterampilan proses agar mampu menjelajahi dan memahami alam sekitar. 
Berdasarkan hasil observasi peneliti di SMP Laboratorium Universitas Negeri Malang, dalam proses pembelajarannya keterampilan proses sains peserta didik masih kurang; peserta didik masih kesusahan dalam mengamati obyek yang dipelajari dengan tepat, sehingga hasil yang didapatkan tidak sesuai dengan tujuan pembelajaran, menggunakan alat dan bahan yang tidak terkontrol, serta pengumpulan data yang tidak rapi, serta dalam kemampuan psikomotorik peserta didik masih kurang.

Berdasarkan pemaparan di atas, maka tujuan penelitian ini adalah untuk melihat pengaruh pendekatan inkuiri terbimbing berbantuan modul belajar berpengaruh terhadap keterampilan proses sains dan hasil belajar psikomotorik.

\section{METODE PENELITIAN}

Penelitian ini tergolong eksperimen semu (quasy experimental design), yaitu jenis penelitian dimana peneliti tidak dapat melakukan pengendalian dan tindakan secara penuh (Sugiyono, 2012), khususnya non equivalent control group design.Populasi target pada penelitian ini adalah peserta didik kelas VIII SMP Laboratorium Universitas Negeri Malang terdiri atas empat kelas dengan total 150 peserta didik. Sampel dalam penelitian ini adalah peserta didik kelas VIII B dan VIII C dengan total 75 peserta didik. Pada kelas VIII C, dan kelas VIII menggunakan pembelajaran multistrategi. Teknik pengambilan sampel menggunakan teknik simple random sampling dengan cara pengundian.

Instrumen yang akan digunakan dalam penelitian ini adalah tes keterampilan proses sains, lembar pengamatan hasil belajar psikomotorik, dan angket respons peserta didik terhadap pembelajaran pendekatan Inkuiri Terbimbing. . Dalam hal ini yang bertugas sebagai pengamat (observer) yaitu saudari Renda Suri Pratimi, S.Pd., Nurmiati, S.Pd., dan Ulfa Lutfiah.

Tes keterampilan proses sains yang digunakan berupa tes uraian, terdiri dari empat soal yang mewakili tiap aspek penilaian, yaitu (1) menyusun hipotesis (2) mengamati, (3) menganalisis, 
serta (4) menyimpulkan. Pemberian nilai diberikan dengan nilai tertinggi 100 dan terendah 0 , dimana soal tiap butir memiliki skor berdasarkan tingkat kesulitan.Keterampilan psikomotorik yang dinilai meliputi; (1) mengamati, (2) bertanya, (3) mencoba, (4) menalar, dan (5) menyaji. Format isian yang disediakan terdiri dari kolom-kolom aspek penilaian dengan pemberian skor didasarkan pada alternatif : Sangat Tepat (ST), Tepat (T), Kurang Tepat (KT), dan Tidak Tepat (TT). Penilaian ini dianalisis secara deskriptif kuantitatif dengan presentase. Selanjutnya data hasil penelitian dianalisis menggunakan Ancova (Analysis of Covariance) pada taraf signifikan $\boldsymbol{\alpha}=0,05$, dengan bantuan program SPSS 21 for Windows.

\section{HASIL DAN PEMBAHASAN}

Deskripsi data keterampilan proses peserta didik pada kelas eksperimen dan kelas kontrol disajikan dalam Tabel 1.

\section{Tabel 1}

Deskripsi data keterampilan proses peserta

\begin{tabular}{|l|c|c|l|c|c|l|}
\hline \multirow{3}{*}{ Indikator } & \multicolumn{5}{|c|}{ Keterampilan Proses Sains } & \\
\cline { 2 - 3 } & Kelas Perlakuan & Peningkatan & Kelas Kontrol & Peningkatan \\
\cline { 2 - 3 } \cline { 5 - 7 } & Pre & Post & & Pre & post & (\%) \\
\hline $\begin{array}{l}\text { Menyusun } \\
\text { Hipotesis }\end{array}$ & 46.30 & 87.96 & 41.67 & 35.90 & 70.94 & 35.04 \\
\hline Mengamati & 37.50 & 74.07 & 36.57 & 34.19 & 74.36 & 41.88 \\
\hline Menganalisis & 26.04 & 72.92 & 47.57 & 27.56 & 58.65 & 31.73 \\
\hline Menyimpulkan & 40.74 & 88.89 & 50.93 & 52.99 & 91.45 & 40.17 \\
\hline
\end{tabular}

Tabel 1 menunjukkan bahwa setiap indikator mengalami peningkatan, yaitu indikator menyusun hipotesis, menganalisis, dan menyimpulkan pada peserta didik kelas perlakuan dibandingkan dengan kelas kontrol. Peningkatan keterampilan proses sains tertinggi adalah pada indikator menyimpulkan yaitu sebesar $50.93 \%$. 
NENENG AGUSTININGSIH, DKK.

Secara keseluruhan perbandingan presentase peningkatan seatiap indikator keterampilan proses sains pada kelas perlakuan, dan kelas kontrol terdapat pada Gambar 1 sebagai berikut.

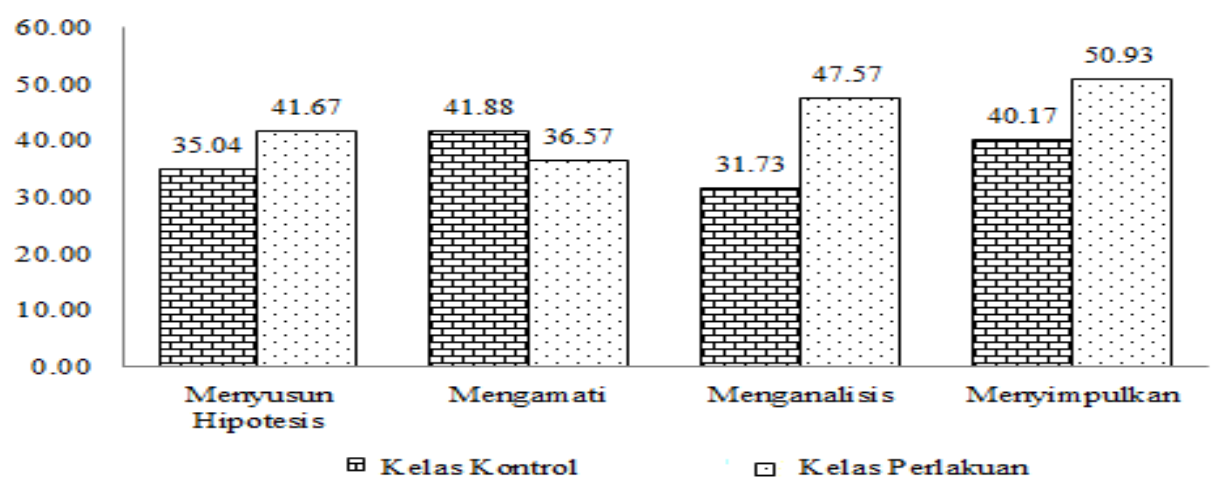

Gambar 1

Presentase Peningkatan Hasil Tes Keterampilan Proses Sains pada Setiap Indikator

Hasil belajar psikomotorik diperoleh dari hasil pengamatan.Deskripsi data hasil belajar psikomotorik peserta didik pada kelas eksperimen dan kelas kontrol disajikan dalam Tabel 2.

\section{Tabel 2}

Deskripsi Data Hasil Belajar Psikomotorik Peserta Didik

\begin{tabular}{|c|c|c|c|c|c|c|c|c|}
\hline \multirow{2}{*}{ Kelas } & \multicolumn{6}{|c|}{ Indikator } & \multirow{2}{*}{$\begin{array}{l}\text { Rerat } \\
\text { a }\end{array}$} & \multirow{2}{*}{$\begin{array}{l}\text { Kriteri } \\
\text { a }\end{array}$} \\
\hline & $\mathrm{A}$ & B & $\mathrm{C}$ & D & $E$ & $F$ & & \\
\hline $\begin{array}{l}\text { Perlakua } \\
\text { n }\end{array}$ & $\begin{array}{l}89,5 \\
3\end{array}$ & $\begin{array}{l}69,1 \\
2\end{array}$ & $\begin{array}{l}83,8 \\
1\end{array}$ & $\begin{array}{l}75,6 \\
9\end{array}$ & $\begin{array}{l}76,5 \\
0\end{array}$ & $\begin{array}{l}85,5 \\
8\end{array}$ & 80,04 & Baik \\
\hline Kontrol & $\begin{array}{l}82,4 \\
3\end{array}$ & $\begin{array}{l}67,0 \\
4\end{array}$ & $\begin{array}{l}80,2 \\
9\end{array}$ & $\begin{array}{l}70,9 \\
4\end{array}$ & $\begin{array}{l}68,7 \\
5\end{array}$ & $\begin{array}{l}81,4 \\
1\end{array}$ & 75,14 & Baik \\
\hline
\end{tabular}

Keterangan : A : Mengamati, B :Menanya, C :Mencoba, $\mathrm{D}$ :Menalar, E :Menyajikan, F :Mencipta

36 BIOTA: Jurnal Tadris IPA Biologi FITK IAIN Mataram 
Penilaian psikomotorik kelas perlakuan memiliki nilai rerata 80,04 yang termasuk dalam krtiteria Baik. Hasilbelajar psikomotorik berdasarkan nilai pada setiap indikator pada kelas perlakuan berbeda signifikan dengan kelas kontrol.

\section{Hasil Uji Prasyarat}

a. Uji normalitas

Hasil uji normalitas data dilakukan dengan uji signifikan Kolmogorov-Smirnov dengan program SPSS 21 for Windows. Data keterampilan proses sains merupakan data berdistribusi normal, dimana Sig. KolmogorovSmirnov $(0,368 ; 0,526 ; 0,304 ; 0,734)>0,05$.

\section{Tabel 3}

Hasil Uji Normalitas Data Keterampilan Proses Sains

\begin{tabular}{|l|c|c|c|c|c|}
\hline \multirow{2}{*}{ Variabel } & \multicolumn{4}{|c|}{ Sig. Kolmogorov-Smirnov } & \multirow{3}{*}{ Kategori } \\
\cline { 2 - 5 } & Kelas Perlakuan & \multicolumn{2}{|c|}{ Kelas Kontrol } & \\
\cline { 2 - 5 } & Pretes & Postes & Pretes & Postes & \\
\hline $\begin{array}{l}\text { Keterampilan } \\
\text { Proses Sains }\end{array}$ & 0,368 & 0,526 & 0,304 & 0,734 & Normal \\
\hline
\end{tabular}

b. Uji homogenitas

Hasil uji homogenitas data dilakukan dengan uji rumus Levene dibantu dengan program SPSS 21 for Windows. Data keterampilan proses pada nilai Levene Statisticpretes $(1,032,2,497)$ dan postes $(0,057,1,194)>\mathrm{F}$ tabel $(3,13)$, maka data dikatakan homogen. 
NENENG AGUSTININGSIH, DKK.

\section{Tabel 4}

Hasil Uji Homogenitas Data Keterampilan Proses Sains

\begin{tabular}{|c|c|c|c|c|c|}
\hline \multirow{2}{*}{ Variabel } & \multicolumn{2}{|c|}{ Levene Statistic } & \multicolumn{2}{c|}{ Significant } & \multirow{2}{*}{ Kategori } \\
\cline { 2 - 5 } & Pretes & Postes & Pretes & Postes & \\
\hline $\begin{array}{l}\text { Keterampilan } \\
\text { Proses Sains }\end{array}$ & 1,032 & 0,057 & 0,313 & 0,812 & Homogen \\
\hline
\end{tabular}

\section{Hasil Uji Hipotesis}

Hasil uji hipotesis keterampilan proses sains pada taraf signifikan 5\% dapat ditampilkan pada Tabel 5.

\section{Tabel 5}

Hasil Uji Hipotesis Keterampilan Proses Sains

\begin{tabular}{|c|c|c|c|c|c|}
\hline Source & $\begin{array}{l}\text { Type III } \\
\text { Sum of } \\
\text { Squares }\end{array}$ & $d f$ & $\begin{array}{l}\text { Mean } \\
\text { Square }\end{array}$ & $F$ & Sig. \\
\hline $\begin{array}{l}\text { Corrected } \\
\text { Model }\end{array}$ & 7800.069 & 2 & 3900.035 & 4.991 & 0,000 \\
\hline Intercept & 10158.530 & 1 & 10158.530 & 118.455 & 0,000 \\
\hline$X$ (Pretes) & 6713.811 & 1 & 6713.811 & 78.288 & 0,000 \\
\hline Metode & 428.034 & 1 & 428.034 & 4.991 & 0,029 \\
\hline Error & 6174.597 & 72 & 85.758 & & \\
\hline Total & 436600.000 & 75 & & & \\
\hline $\begin{array}{l}\text { Corrected } \\
\text { Total }\end{array}$ & 13974.667 & 74 & & & \\
\hline
\end{tabular}

Berdasarkan hasil uji statistik anakova angka $\mathrm{F}$ tabel untuk df1, dan df2 = 75 dengan taraf nyata 5\% adalah 3,98. Maka nilai $F_{\text {hitung }}(4,991)>F_{\text {tabel }}(3,98)$, dan Sig. $(0,029)<0,05$, maka $\mathrm{H}_{0}$ ditolak. Sehingga pada kepercayaan 95\%, terdapat pendekatan Inkuiri Terbimbing berbantuan modul belajar terhadap keterampilan proses sains. 


\section{PEMBAHASAN}

Hasil penelitian ini menunjukkan bahwa pendekatan inkuiri terbimbing berbantuan modul belajar pengaruh signifikan terhadap keterampilan proses sains dan hasil belajar psikomotorik peserta didik, hal ini dikarenakan terdapat karakteristik dalam proses pembelajarannya, dimana karakteristik tersebut berpengaruh pada ketempilan proses sains dan hasil belajar psikomotorik. Hasil penelitian ini didukung oleh hasil penelitian Pujiastuti (2012) yang menyimpulkan bahwa pembelajaran Inkuiri terbimbing berpengaruh terhadap keterampilan proses sains peserta. Proses pembelajaran yang dilakukan yaitu 1) menyusun hipotesis; guru mendorong agar peserta didik dapat membuat jawaban sementara atau prediksi berdasarkan masalah yang dikaji, 2) mengamati; peserta didik melakukan keterampilan dalam mengukur, menghitung, mengendalikan, merancang, dan mengumpulkan data, sehingga akan membantu peserta didik dalam membentuk konsep yang telah ditemukan melalui pengamatan, 3) menganalisis; peserta didik mengerjakan dan mengisi pertanyaan analisis terkait percobaan dan pengamatan, dan 4) menyimpulkan; penarikan kesimpulan dalam kelompok berdasarkan hipotesis yang diajukan, dan penarikan kesimpulan bersama-sama guru dalam kelas. Peningkatan keterampilan proses sains dapat dilihat pada nilai presentase peningkatan kelas perlakuan sebesar $43,32 \%$, dibandingkan dengan nilai presentase peningkatan kelas kontrol, yaitu 36,19\%. Pembelajaran biologi dengan menggunakan pendekatan inkuiri terbimbing berbantuan modul belajar mengkondisikan peserta didik terlatih mencari dan menemukan konsep pada materi Memahami Sistem pada Tumbuhan.

Pengukuran hasil belajar psikomotorik peserta didik dilaksanakan pada saat kegiatan pembelajaran. Hasil analisis deskriptif menunjukkan pada penerapan pendekatan inkuiri terbimbing berbantuan modul belajar pada kriteria Baik, yaitu 80,04. Penilaian psikomotorik meliputi indikator 1) mengamati; merupakan kegiatan yang dilakukan dengan melihat, melakukan, atau mengunjungi objek secara langsung. Menurut Aprilianty 
(2013) menyatakan bahwa, mengamati mengutamakan kebermaknaan proses pembelajaran (meaningfull learning). 2) menanya; dalam mengajukan pertanyaan-pertanyaan saat pembelajaran tidak terlalu aktif, namun baik, 3) mencoba; kegiatan peserta didik dalam melakukan atau mengerjakan percobaan,4) menalar; merupakan kegiatan peserta didik dalam menganalisis pertanyaan-pertanyaan dalam LKS yang mendukung konsep dari permasalahn yang dikaji, menerjemahkan suatu informasi yang diamati menjadi konsep yang logis dan dapat dipertanggungjawabkan. 4) menyajikan; menyampaikan hasil kelompok pada kelompok lain melalui presentasi di depan kelas, yang diperoleh dari pengamatan, analisis, dan kesimpulan kegiatannya, dan 5) mencipta; membuat tabel hasil pengamatan, serta membuat laporan hasil percobaan berdasarkan informasi yang telah dianalisis.

\section{KESIMPULAN}

Berdasarkan hasil analisis data mengunakan uji statistik anakova terhadap keterampilan proses sains dan hasil belajar kognitif peserta didik diperoleh $F_{\text {hitung }}>F_{\text {tabel, }}$ dan nilai $\operatorname{Sig}<_{0,05}$, maka $\mathrm{H}_{0}$ ditolak. Sehingga pada kepercayaan 95\%, terdapat pengaruh pendekatan Inkuiri Terbimbing berbantuan modul belajar terhadap keterampilan proses sains, dan hasil belajar psikomotorik.

\section{DAFTAR PUSTAKA}

Aprilianty, E. 2013.Pendekatan Ilmiah dalam Proses Pembelajaran Sejarah. Implementasi Kurikulum 2013 Melalui Pendekatan Ilmiah, (Online) (http://faktoer.wordpress.com), diakses10 Januari2014.

Bilgin, I. 2009. The Effects of Guided Inquiry Instruction Incorporating A Cooperative Learning Approach on University Students Achievement of Acid And Bases 
Concepts and Attitude Toward Guided Inquiry Instruction. Scientific Research and Essay, 4 (10):1038-1046.

Dahniar, N. 2006. Science Project Sebagai Salah Satu Alternatif dalamMeningkatkan Keterampilan Proses Sains di SMP. Jurnal Pendidikan Inovatif. 2(1): 35-39.

Departemen Pendidikan Nasional. 2002. Model Pembelajaran IPA Terpadu. Jakarta: Pusat Kurikulum.

Harrow, W. 2011. Methodes of Teaching shop and Technical Subjects. Ney York: Delmal Publishing. Journal Science,Vol. 17 (2): 160-163.

Kementrian Pendidikan dan Kebudayaan.2013. Konsep Pendekatan Scientific (Powerpoint). Jakarta: BPSDMP

Kulthau, CC.,Maniotes, LK., \&Caspari, AK.2007. Guided Iquiry: Learning in $21^{\text {th }}$ Century School. New York: Library Unlimited Inc.

Lane, D.W. 2007. An Activity models for Scientific. The Science Teacher. Vol 71 (1): 44-46.

Lie, C., Hong, J., \& Tseng, Y. 2007. The Effectiveness of InquiryBased Learning by Scaffolding Students to Ask "5 Why" Questions. Journal Reserach and Practice. Vol 1 (3): 20-26. Diakses tangga 10 Januari 2014.

Nasution, S. 2005. Berbagai Pendekatan dalam Proses Belajardan Mengajar.Jakarta; Bumi Aksara.

Pujiastuti, P. 2012. Model Inkuiri Terbimbing dipadu TGT serta Pengaruhnya Terhadap keterampilan Proses Sains dan Hasil Belajar Biologi Siswa kelas V SD di Kota Wates. Tesis tidak diterbitkan. Malang: Pascasarjana Universitas Negeri Malang

Rustaman, N. 2005.Perkembangan Peneltian Pembelajaran Berbasis Inkuiri Dalam Pendidikan Sains. Makalah disajikan dalam Seminar Nasional II, Fakultas Pendidikan MIPA Universitas Pendidikan Indonesia, Bandung 23 Juli 2005.

Twining, J.,E. 1991. Strategies for Active Teaching. Boston London: Ally And.

Widoretno, S. 2012. Strategi Pembelajaran Guided Inquiry Sebagai Usaha Mengembangkan Kecakapan Hidup Melalui Mata Pelajaran Biologi di SMP Surakarta.Disertas.Tidak 
NENENG AGUSTININGSIH, DKK.

diterbitkan.Malang :Pascasarjana Universitas Negeri Malang. 